\title{
Near Field Photometry
}

\begin{abstract}
Paper describes deficiencies of conventional method for luminous intensity curve measuring and it brings comparison with newly used methods of near field photometry. There is also presented demonstration measurement of problematic type of luminaire with use of near field photometry.
\end{abstract}

Keywords: luminous intensity curves, near field photometry.

\section{Introduction}

The term "photometry" is used for an optical field of study concerning visible radiation (light) from the view of vision organ. For description of such radiation there are used several specific quantities - luminous intensity, luminous flux etc. During measurement of these quantities there are often used some simplified assumptions that consider light source as a point. For such assumption, to consider luminaires with real dimensions as point sources, it is necessary to keep sufficient distance between measured objects and the measurement places. By fulfilling this condition the ratio between photometrical distance and longest dimension of the optically active part of the luminaire is high enough and the physical dimensions of such luminaire can be neglected. [4] Practical measurement requires this ratio over $5: 1$, photometrical distance should exceed the longest dimension of optically active part of luminaire at least 5times. To keep photometrical distance long enough at the type 1 goniophotometer (rotating the luminaire) is usually not a big issue. But there is another one. Firstly the operational position of the luminaire is varying when measuring with type 1 goniophotometer. This fact can affect the measurement results especially at the luminaires with discharge lamps. Any change of luminaire's operational position has significant influence on its luminous flux, chromaticity temperature and also temperature. Consequent issue lies also with problematical fixation of fragile hanging glass luminaires to the goniophotometer. Solution of this issue may lie in use of another goniophotometer type with fixed position of luminaire that is being measured with moving photometer. However this solution is often confronted with insufficient photometrical distance.

Other significant issue that affects measurement results is the use of dimension simplification process itself. E. g. linear luminaire with length of $150 \mathrm{~cm}$ is often measured with photometrical distance of $10 \mathrm{~m}$ and measurement results are then used for calculation with the distance of reference area from luminaire of $2-3 \mathrm{~m}$. For such short distances the luminaire can be no longer considered as a point source and the calculation is not accurate anymore.

Smart solution of presented deficiencies can be found in use of near field photometry. Two essential differences between conventional (far field) and near field photometry lie in short photometry distance between measured object and measuring sensor and in type of measuring sensor. Luminaire is always fixed in its operational position and its photometrical parameters are measured with sensor moving around the luminaire with photometrical distance of approx. $1 \mathrm{~m}$. Conventional photosensor has to be replaced with luminance analyzer (luminance camera) with ability to record luminance distribution field on the surface of the luminaire. Such luminaire is no longer considered as a point source, but it is considered as a light area.

\section{Operational position}

As presented above one of the key factors at photometrical measurement lies in the operational position of luminaire or light source respectively. Any change of operational position induces change of luminous flux and change of luminance distribution of the discharge lamp. Due to this fact the fixed position of these types of luminaires is required and the measurement is performed with moving sensor.

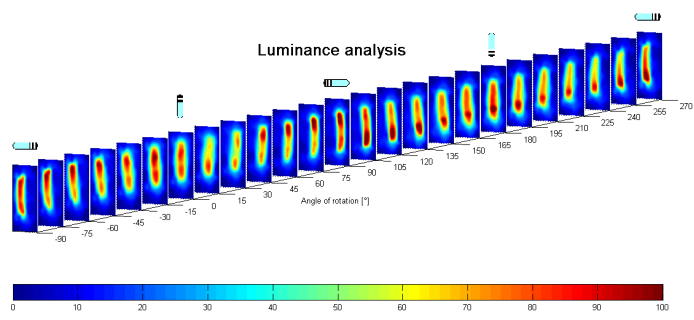

Fig.1. Luminance analysis of discharge arc tube [10]

Fig. 1 presents the influence of operational position of discharge tube of lamp Philips HPI-T 400W on luminance distribution field [11]. Because the luminance is related to luminous flux [5] (1)

$$
L=\frac{d^{2} \Phi}{d A \cdot d \Omega \cdot \cos \beta}
$$

it can be verified that the luminous flux also depends on operational position.

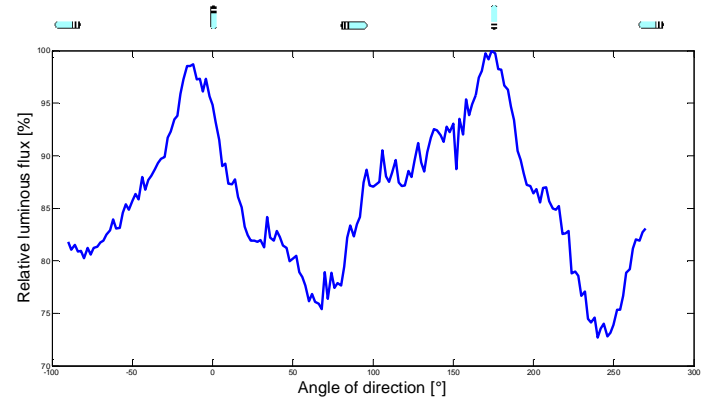

Fig.2. Luminous flux of discharge arc tube

Light sources with highest dependence of luminous flux on operational position are the discharge lamps with wide arc tube (metal-halide lamps) and some compact fluorescent lamps. Besides the change of luminous flux there can be 
often observed the change of light spectrum that affects the chromaticity temperature of light. This phenomenon is mostly present at the high-pressure discharge lamps.

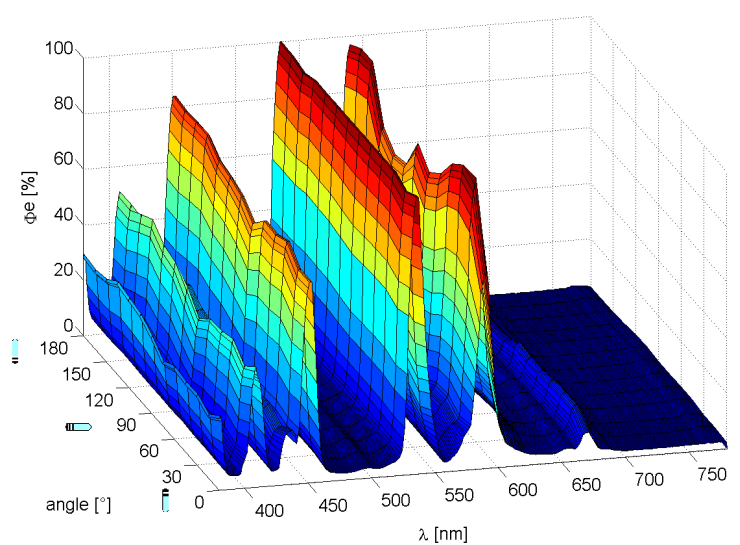

Fig.3. Spectrum change depending on the discharge lamp position

With use of near field photometry the above mentioned effects are negligible, because the light sources work in fixed position.

\section{Influence of photometrical distance}

Conventional measuring method (far field photometry) consider luminaires as point sources. This simplification is based on measurement principle that the illuminance is measured at specified photometrical distance for each position of the luminaire and then the luminous intensity is calculated according to relation (2):

$$
I=E \cdot l^{2}
$$

Particular issue of this equation lies in fact, it can be used for point luminaires. Due to this fact the photometrical distance has to be long enough so the dimensions can be neglected. This fact induces certain error that results from illuminance calculation performed from luminous intensity curve that is measured at sufficiently long photometrical distance. It can be assumed that using this curve for calculation of luminaire mounted with shorter distance will cause calculation error. This situation occurs at most cases of illuminance calculation.

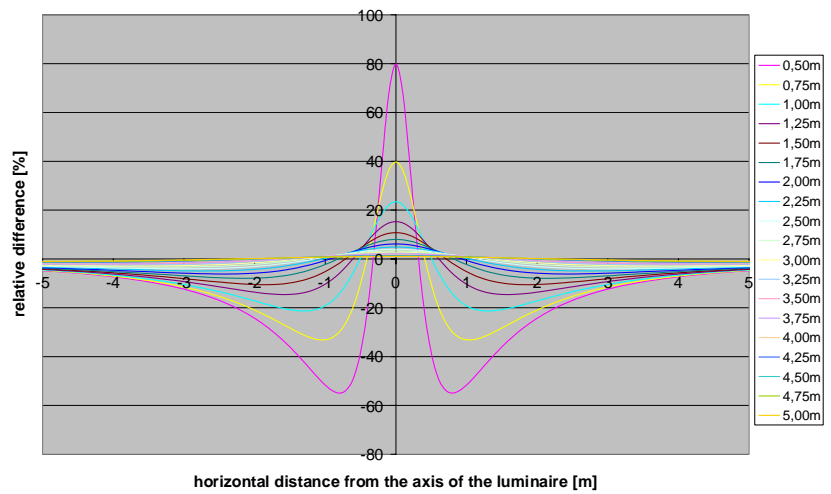

Fig.4. Relative illumination difference from cosine luminaire

This case can be demonstrated in example [9], presented in Fig. 4. In this case the luminaire with cosine intensity curve with longest dimension of optically active area of $1 \mathrm{~m}$ is used. Intensity curve is measured with photometrical distance $10 \mathrm{~m}$ and it is used for simulation of different photometrical distances. The relative error curve from the real value can be observed in Fig. 4. Software developers usually reduce the influence of this error by dividing the luminaire into partial segments with the luminous intensity curves reduced proportionally to number of segments.

\section{Near field photometry}

As presented above, using of near field photometry may prevent measurement from calculation errors mentioned in previous chapters. For measuring of discharge lamp luminaires sensitive to operational position changes or luminaires with complicated fixture to the type 1 goniophotometer the best choice is fixing the luminaire to the operational position and measuring the luminous intensity curves with the moving sensor [2]. If the condition $5: 1$ of photometrical distance is fulfilled, the measurement is simple. If sufficient distance compared with longest dimension of optically active part cannot be achieved it is the proper situation for using near field photometry.

Necessary condition for this measurement is replacing illuminance meter with the luminance analyzer. This device is based on digital camera principle. It can record the picture of light source luminance or luminance of whole luminaire to its chip (CCD or CMOS). Generally all digital (or film) camera records the picture of captured scene to its chip (film). If the proper dimensions of camera position to the captured scene are recorded (no problem at using with goniophotometer) and if there are captured multiple pictures for different positions, the luminous intensity curve of the luminaire can be reconstructed according to (1).

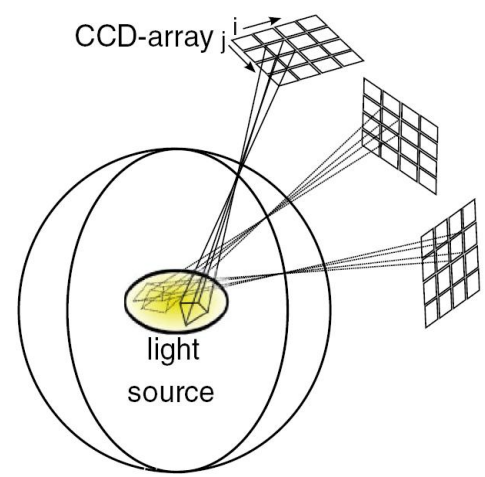

Fig.5. Principle of near field scanning [8]

Fig. 5 presents the principle of near-field scanning of light source with use of luminance analyzer. Each pixel defines by its dimensions the elementary spherical angle $d \Omega$ and if the pixel excitation is proportional to luminance $L$, this value is also proportional to luminous flux $d \Phi$ hitting the pixel surface. If all geometric data of mutual position of luminaire and luminance analyzer are known, using of mathematical algorithms leads to reconstruction of whole luminous intensity curve, as it would have been measured from any distance. Considering the distribution of luminous flux into the space from the light source obtained by use of near field photometry is precise measuring method, final design of lighting system is much more accurate.

Key disadvantage of near field photometry lies in necessity of processing enormous amount of data. Amount of data is related to measurement accuracy and recording chip resolution. For cameras of these days with high resolution chips it is common to record millions of values at one measurement. This amount is multiplied by number of captured pictures that have to be processed consequently. Processing of such amount of data needs sufficient computing performance that increases the price of such measurement in comparison with conventional methods rapidly. Nevertheless resulting data format is currently quite 
large (hundreds of $\mathrm{MB}$ ) so the distribution over internet of such data is not ideal. Resulting file is the type Rydat, it keeps the detailed information about directional characteristics of light source so it is currently often used for mathematical modelling of luminaire optical parts. Legislative standards of this type of solution is currently solved at CIE level, e. g. technical committees TC2-59 and TC2-62.

Our department supervised several diploma theses issued with this theme including the optimization of computing algorithm, measurement performing etc. Demonstration measurement was performed with glass hanging luminaires, their construction made impossible fixing the luminaires to the type 1 goniophotometer. One of the measurement samples was hanging tube luminaire LUCIS - Maia that is not measurable in any position than hanging one.
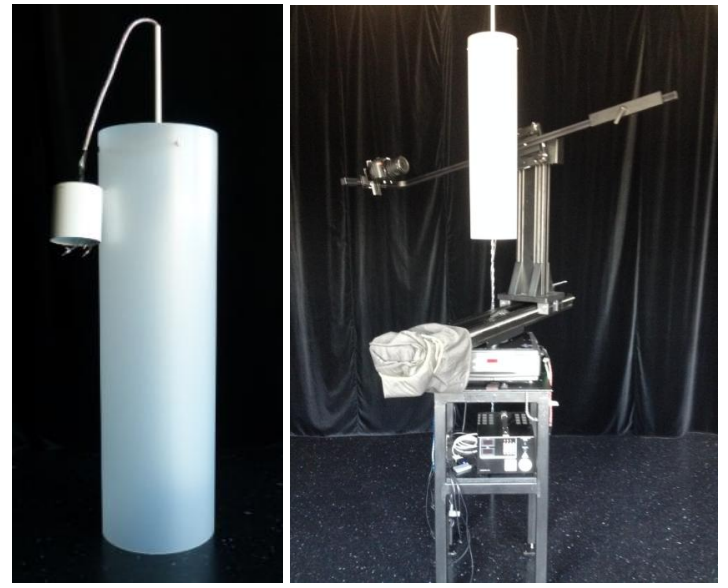

Fig.6. Maia luminaire (product and measuring preview) [7]

Luminaire is equipped with two compact fluorescent lamps OSRAM DULUX L 80W/830 that are installed in vertical position inside of the luminaire. According to vertical length of luminaire $800 \mathrm{~mm}$ the photometrical distance should exceed $4 \mathrm{~m}$. That is complicated task, because a goniophotometer with so long arm is not available on the market.

Czech calibrated luminance analyzer LDA - LumiDISP based on digital camera NIKON was used for measurement [1]. Evaluation of the measurement was performed in LumiDISP software that is being developed consequently with the luminance analyzer at our department.

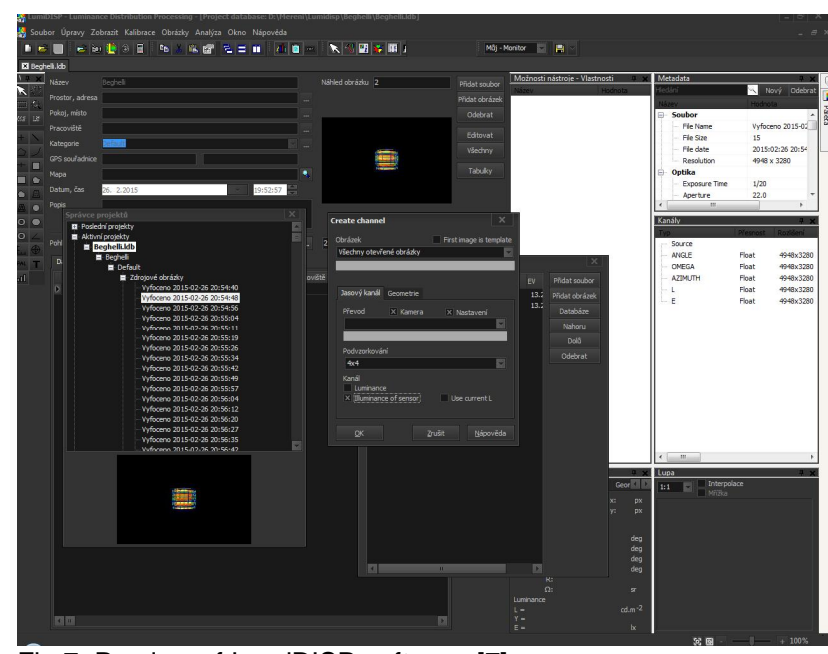

Fig.7. Preview of LumiDISP software [7]
Luminaire was scanned from different views to provide sufficient coverage of luminance scans.

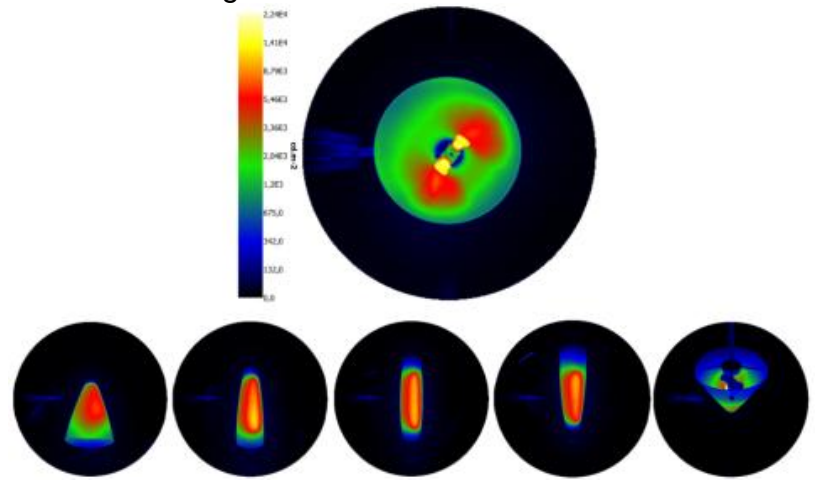

Fig.8. Example of luminance images of Maia luminaire (for angles $\left.0^{\circ}, 30^{\circ}, 60^{\circ}, 90^{\circ}, 120^{\circ}, 165^{\circ}\right)[7]$

These scans were used for reconstruction of luminance intensity curve with use of sophisticated algorithm as if they would have been measured from different photometrical distances [3], [6].

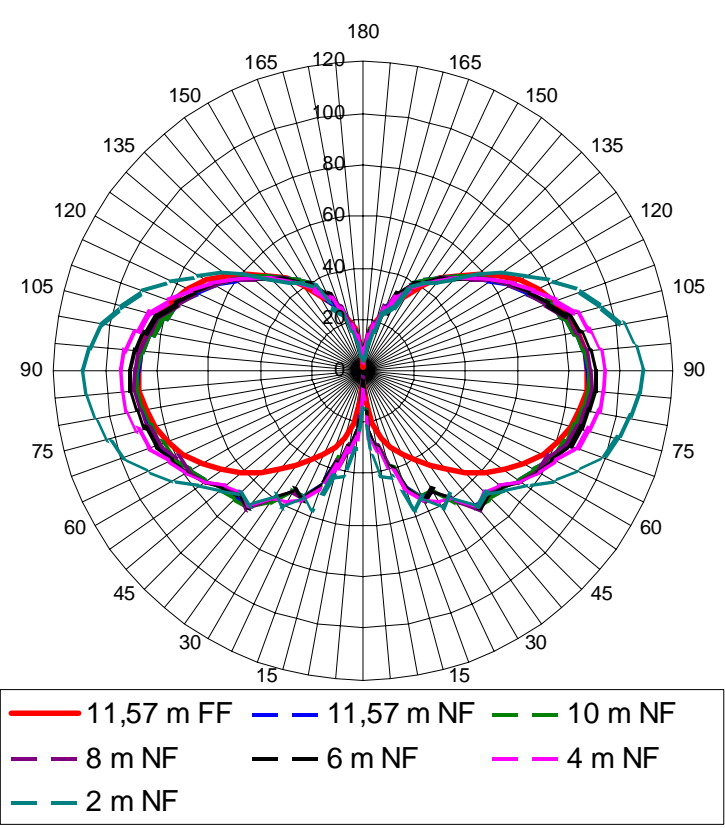

Fig.9. Recalculated luminous intensity curves of MAIA luminaire

Fig. 9 presents several luminous intensity curves. Red curve was measured with conventional method (FF = far field), the luminaire was fixed to the goniophotometer with special mechanism in horizontal position. This measurement is in a way influenced with error due to change of light sources operational position. Other error was caused by shadow from the mounting construction of goniophotometer. This fact explains minor differences between FF curve and other curves measured with use of near field photometry (NF). Mutual differences among NF curves were expected due to different photometrical distances.

\section{Conclusion}

Near field photometry brings thanks to modern digital technology and high performance computers new possibilities of measuring that were complicated even few years ago. Near future promises consequent upgrade of measuring technology for this method and legislative 
confirmation of near field goniophotometers as a standard measuring devices. Currently data obtained from near field goniophotometers are used for design of optical parts of discharge lamp lumianires and also LED luminaires. Using of sophisticated algorithms enables simplification of these data to the form of luminous intensity curves, but it is necessary to consider the fact that calculation based on luminous intensity curves may be influenced with error caused by short photometrical distance in specific cases.

\section{Acknowledgement}

This research work has been carried out in the Centre for Research and Utilization of Renewable Energy (CVVOZE). Authors gratefully acknowledge financial support from the Ministry of Education, Youth and Sports of the Czech Republic under NPU I programme (project No. LO1210). Authors also thanks for the assistance during the measurement to Mr. Tomáš Kutý and Mr. Jakub Št’astný and for providing luminaires to measuring to producer LUCIS s.r.o.

\section{REFERENCES}

11] BAXANT, P.; SUMEC, S; ŠKODA, J. Lumidisp. UEEN VUT V BRNĚ. Lumidisp [online]. http://www.lumidisp.eu/

[2] BREDEMEIER, K.; POSCHMAN, R.; SCHMIDT, F. Nahfeldgoniophotometer - Systeme zur messung der Lichtverteilungen an Leuchten: Lampen und LED. Licht. 2006.

[3] DUBNICKA, R.; GASPAROVSKÝ, D.; RADITSCHOVA, J. Proposal for Guideline of Verification Lighting Systems Acording to ISO 8995-1:2002(E)/CIE S008/E:2001, PROCEEDINGS of CIE 2014 „Lighting Quality and Energy Efficiency", Kuala Lumpur, Malaysia, ISBN 978-3-902842-49-7

[4] HABEL, J.; BÁLSKÝ, M. Analysis of measurement uncertainty luminous intensity curves on goniophotometer (in czech: Rozbor nejistoty měření čar svítivosti na goniofotometru), In Kurz osvětlovací techniky XXVII. Ostrava: VŠB - Technická univerzita Ostrava, 2009, s. 59-65. ISBN 978-80-248-2087-3.

[5] HABEL, J.; DVOŘÁČEK, K.; DVOŘÁČEK, V.; ŽÁK, P. 2013. Světlo a osvětlování, 1st ed. Prague: FCC Public, ISBN 978-80-86534-21-3

[6] JACOBS, V ; FORMENT, S ; ROMBAUTS, P ; HANSELAER, $P$. Near-field and far-field goniophotometry of narrow-beam
LED arrays, in "Lighting Research \& Technology", 2015 Jun, Vol.47(4), pp.470-482, ISSN: 1477-1535;

[7] KUTÝ, T. Near field photometry (in czech: Blízká fotometrie). Brno: Brno university of technology, 2015. Master's thesis. Supervisor: Ing. Jan Skoda, Ph.D.

[8] SCHMAHLING, F.; WUBBELER, G.; LOPEZ, M.; GASSMAN, F.; KRUGER, U.; SCHMIDT, F.; SPERLING, A.; ELSTER, C. Virtual experiment for near field goniophotometric measurements. Applied optics. 2014,

[9] ŠKODA, J.; BAXANT, P. Non- pointed luminaires and their photometry. Przeglad Elektrotechniczny, 2008, roč. 2008, č. 8, s. 44-46. ISSN: 0033- 2097.

[10] ŠKODA, J.; BAXANT, P.; PAVELKA, T.; KRBAL, M.; SUMEC, $\mathrm{S}$. Analysis of Discharge Lamp Luminance Depending on Position. In ELECTRIC POWER ENGINEERING 2011. 1. Ostrava: VSB - Technical University of Ostrava, 2011. s. 1-3. ISBN: 978-80-248-2393-5.

[11]ŠŤASTNÝ, J. The effect of operating position of the light source on the photometric parameters. (in czech: Vliv pracovní polohy světelného zdroje na fotometrické parametry). Brno: Brno university of technology, 2015. Bachelor's thesis, Supervisor: Ing. Jan Škoda, Ph.D.

\section{Authors:}

Ing. Jan Škoda, Ph.D., Brno University of Technology, Technická 3058/12 Czech Republic, e-mail: skoda@feec.vutbr.cz

Ing. Stanislav Sumec, Ph.D., Brno University of Technology, Technická 3058/12 Czech Republic, e-mail: sumec@feec.vutbr.cz

Doc. Ing. Petr Baxant, Ph.D., Brno University of Technology, Technická 3058/12 Czech Republic, e-mail: baxant@feec.vutbr.cz Ing. Michal Krbal, Ph.D., Brno University of Technology, Technická 3058/12 Czech Republic, e-mail: krbal@feec.vutbr.cz

Ing. Tomáš Pavelka, Brno University of Technology, Technická 3058/12 Czech Republic, e-mail: pavelkat@feec.vutbr.cz 